\title{
Models of Gen-gene Interaction in Determining the Severity of Bronchial Asthma in Children
}

\author{
Olena Rechkina ${ }^{1}$, Nataliia Gorovenko ${ }^{2}$, Vira $\operatorname{Stryzh}^{1}$, Zoia Rossokha ${ }^{3}$, Svitlana Kyriachenko ${ }^{3}$, \\ Serhii Rudenko ${ }^{1}$ \\ ${ }^{1}$ Department of Pediatric Pulmonology and Allergology, National Institute of Phthisiology and Pulmonology, Named After Feophil \\ Gavrilovich Yanovskiy NAMS of Ukraine, Kyiv, Ukraine \\ ${ }^{2}$ Shupyk National Medical Academy of Postgraduate Education, Kyiv, Ukraine \\ ${ }^{3}$ Reference Center for Molecular Diagnostics of the Ministry of Health of Ukraine, Kyiv, Ukraine
}

Email address:

rechkina@ifp.kiev.ua (O. Rechkina), strizh@ifp.kiev.ua (V. Stryzh), drrudenko@ukr.net (S. Rudenko)

\section{To cite this article:}

Olena Rechkina, Nataliia Gorovenko, Vira Stryzh, Zoia Rossokha, Svitlana Kyriachenko, Serhii Rudenko. Models of Gen-gene Interaction in Determining the Severity of Bronchial Asthma in Children. American Journal of Internal Medicine. Special Issue: New Approaches to Manage Difficult-to-Control, Severe Asthma. Vol. 8, No. 4, 2020, pp. 182-191. doi: 10.11648/j.ajim.20200804.17

Received: February 14, 2020; Accepted: April 22, 2020; Published: August 4, 2020

\begin{abstract}
Bronchial asthma (BA) has a polygenic nature, and the onset of its manifestation and features course is realized due to the influence of genetic factors. This study aimed to investigate the effect of polymorphisms of the genes of the phase II detoxification system and genes of the cardiovascular tone on the severity of asthma in children. The study included 163 children aged 5-18 years: 38 with severe asthma, 69 with moderate asthma, and 56 with mild asthma. A molecular genetic study was conducted to determine the frequency of gene propagation and gen-gene interaction by GSTT1, GSTM1, GSTP1, ACE, eNOS, AT2R1, NAT2 genes at different severity of bronchial asthma. Found that in the prediction of the severity of asthma special place belongs to the analysis of the combination of genotypes. Independent effects were found for AT2R1 and ACE gene polymorphisms. The ACE (I / D) / AT2R1 (A1166C) / eNOS (T786C) / eNOS (4b / 4a) four-locus model was developed to predict the severe BA course and the need for additional analysis of the interaction of AT2R1 (A1166C) and eNOS (T786C), eNOS (T786C) genes was demonstrated (4b4a) and GSTT1. The risk of developing severe BA has been demonstrated for the combination of 1166SS + 786TT, 1166CC + 786TC genotypes by AT2R1 (A1166C) and eNOS (T786C) genes, and the reduction of this risk for combinations of eNOS (4b4a) 4b4b + GSTT1 genotypes. In moderate asthma, combinations of ACE genotypes DD + AT2R1 1166SS and AT2R1 313AA + GSTP1 1166SS were reliable risk markers for severe asthma. AT2R1 gene polymorphism was the leading marker in more severe asthma. A marker of severe BA was also found for the heterozygous 857GA polymorphism of the NAT2 gene (G857A). Conclusions. The influence of ACE (I / D), AT2R1 (A1166C), eNOS (T-786C), NAT2 (G857A), GSTT1, and GSTP1 gene polymorphisms on the severity of asthma in children has been established.
\end{abstract}

Keywords: Bronchial Asthma, Children, Genotype

\section{Introduction}

Bronchial asthma (BA), as a genetically determined disease, heterogeneous in its clinical manifestations, pathophysiological and immunopathological mechanisms, is characterized by chronic inflammation of the respiratory tract, manifested by the recurrent respiratory symptoms, such as wheezing, shortness of breath, chest tightness and cough, which can vary in intensity and occur together with variable airway obstruction [1]. It is important that no individual genes play a role in the development of BA, but rather the interaction of susceptible genes, both with each other and with different internal and external influences. More than 100 different asthma-associated genes have been identified and their list continues to grow. The largest asthma genetics study was conducted in 2010 by a consortium comprising more than a hundred centers worldwide [2]. The authors performed a genome-wide association search (GABRIEL study) that genotyped 10365 individuals with BA and 16110 individuals 
without BA to test for association between 582892 singlemolecule polymorphisms and asthma. As a result, candidate genes were set on chromosome 2 (ILIRL1/ILI8R1), 6 (HLA$D Q), 9$ (IL33), 15 (SMAD3), 17 (ORMDL3/GSDMB), and 22 $(I L 2 R B)$ that are associated with asthma. The ORMDL3 gene, in particular, was associated with BA that occurred in childhood, and the $H L A-D Q$ gene was associated with older asthma. In addition, the results showed that $38,0 \%$ of all childhood asthma cases were characterized by different combinations of identified genes. The study also found a connection between total serum IgE level and the HLA-DRB1 gene in the class II major histocompatibility complex region on chromosome 6 . However, this locus was not associated with asthma and it was suggested that an increase of $\operatorname{IgE}$ levels in serum plays a minor role in asthma development. These studies have proved that asthma, both genetically and phenotypically, is a highly heterogeneous disorder, and asthma susceptibility genes are broadly divided into three categories related to: 1) immune system functioning, 2) biology and mucous membrane functions, and 3) lungs function and disease expression [3, 4]. However, if the association of the gene with asthma is established in only one study, it does not mean the existence of the connection between this gene and the disease (ADAM33 gene localized on chromosome 20p13; Filaggrin gene on chromosome 1q21, etc.). Therefore, the genetic architecture of BA is now being considered in the context of a polygenic system characterized by the additive effect of the individual genes, each of which is virtually individually incapable of causing the disease [5,6], but internal and external factors are capable of altering gene expression directly or indirectly through the epigenetic changes $[7,8]$.

It is known that the severity of bronchial asthma in children deteriorates significantly depending on the degree of oxidative stress which arises as a result of violations of the mechanisms of peroxidation and enzymatic support of the prooxidant system [9], the accumulation of the defective membrane enzymes of the biotransformation system of xenobiotics, endogenous intermediates of such processes as sensitization, inflammation and bronchoconstriction [10]. In healthy people xenobiotics can be easily removed from the body with the help of the enzymes of the second phase of detoxification system - glutathionetransferase (GSTs; encoded by the genes GSTT1, GSTM1, GSTP1), acetyltransferase (encoded by the genes $N A T 2$, etc.).

Glutathione S-transferase theta-1 is an enzyme that is encoded in humans by GSTT1 gene, localized on chromosome 22q11.23 (Figure 1) and consists of five exons with identical borders of the exon/intron [11].

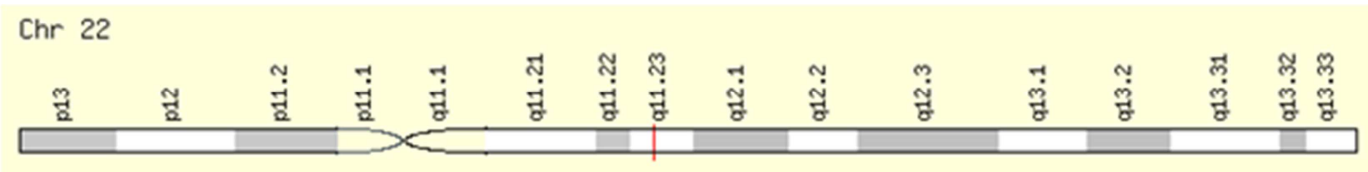

Figure 1. Localization of the GSTT1 gene on chromosome 22.

The GSTM1 gene is organized in the genomic cluster on the chromosome 1p13,3 and is known to be highly polymorphic (Figure 2) and encodes glutathione S-transferase, which belongs to the mu class and is responsible for the detoxification of electrophilic compounds, including environmental toxins and oxidative stress products when combined with glutathione [12].

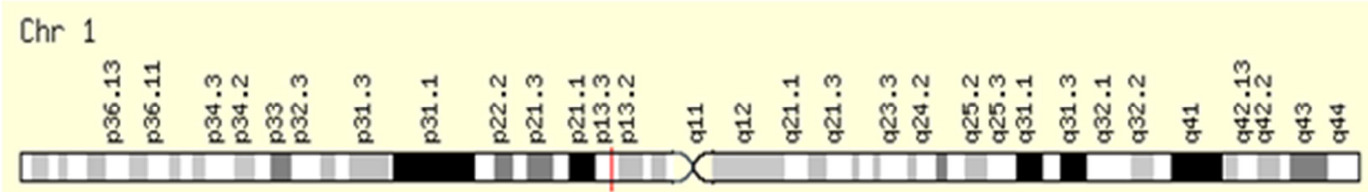

Figure 2. Localization of the GSTM1 gene on chromosome 1.

Taking into consideration the biochemical, immunological and structural properties of the GSTs family and paying attention to the significance of the GSTT1, GSTM1 genes in xenobiotic detoxification, the glutathione S-transferase pi (GSTP1) gene localized on chromosome 11 (Figure 3) should be considered. GSTP1 gene expression is associated with DNA hypermethylation in $\mathrm{CpG}$ islands in promoter-5' [13].

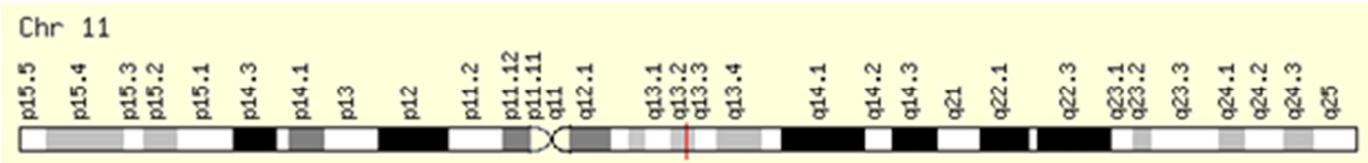

Figure 3. Localization of the GSTP1 gene on chromosome 11

Due to the single nucleotide replacement of adenine (A) by guanine (G) in the GSTP1 gene, which leads to the replacement of the isoleucine amino acids (Ile105) by valine
(Val105), there is a change in the enzymatic activity, which causes an increase in the level of hydrophobic adducts in lung tissue and in polycyclic aromatic hydrocarbons of the 
DNA adducts in blood lymphocytes. The GSTPI polymorphism is a candidate for the development of asthmatic symptoms because it is responsible for catabolism of the lipid by-products and DNA oxidation, influencing the binding of hydrophobic electrophiles and substrate-specific catalytic activity of the enzyme [14].

The gene encoding the cytosolic enzyme NAT2 is localized on chromosome $8 p 22$ (Figure 4).

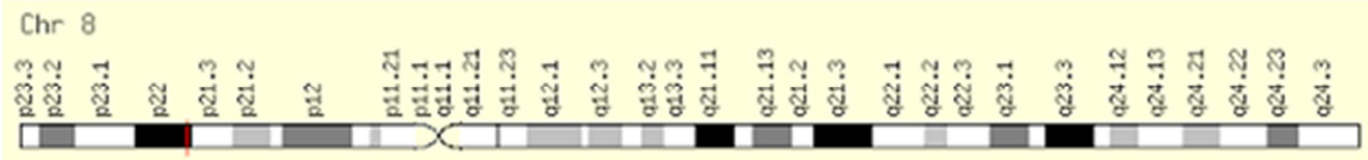

Figure 4. Localization of the NAT2 gene on chromosome 8.

In the pathogenesis of any disease, along with the major genes that provoke the disease, there are always other, minor gene modifiers. Their identification is particularly important in multifactorial diseases such as BA.

It is known that the vasoregulatory function of the body is coordinated by the expression of the individual genes encoding the synthesis of nitric oxide (NO) by the action of the enzyme NO synthase (NOS) and the synthesis of angiotensin converting enzyme (ACE), which are present in the cells of the pulmonary endothelium, monocytes and Tlymphocytes.

The eNOS encoding gene is located on the chromosome 7q35-36 and has 26 exons. The eNOS gene promoter contains several domains, ie it can be regulated by a number of transcription factors (Figure 5) [15].

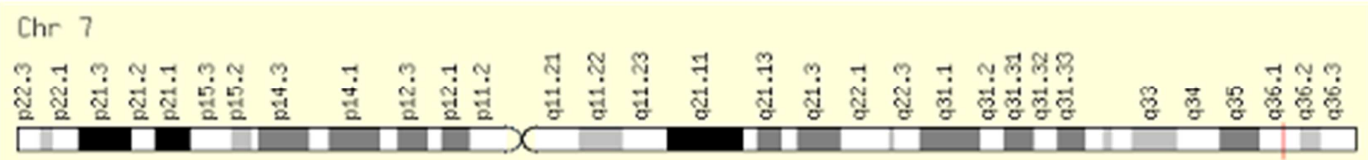

Figure 5. Localization of the eNOS gene on the chromosome.

$A C E$ is a key component of the renin-angiotensin system, the most important humoral pressure regulator. The formation of angiotensin II - the main vasoconstrictor and degradation of bradykinin - an important vasodilator takes place under the influence of this enzyme, which also enhances the proliferation and contractility of the smooth muscle of the respiratory tract, thereby contributing to the excessive bronchus. The angiotensin-converting enzyme gene $-A C E$ is localized on the long arm of the 17 th chromosome at the 17q23 locus, it consists of 26 exons and 25 introns, and its size is 45,000 bp. (Figure 6) [16].

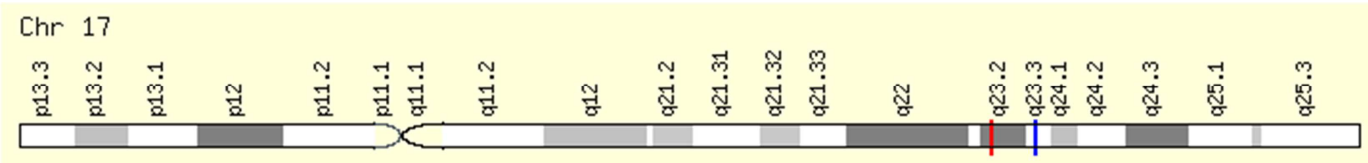

Figure 6. Localization of the ACE gene on the chromosome 17.

Another important unit is the gene of the receptor of angiotensin of the 2 nd type $1(A T 2 R 1)$. The changes in the expression or structure of a $A T 2 R 1$-receptor due to the polymorphism of its gene may lead to the changes in the regulation of the vascular tone and proliferation of vascular wall elements. The Gene of the receptor 1 for angiotensin II $(A T 2 R 1)$ is located on the long arm of the 3 rd chromosome at the locus 3q21-q25, contains 5 exons and consists of about 55 t. p. (Figure 7) [17].

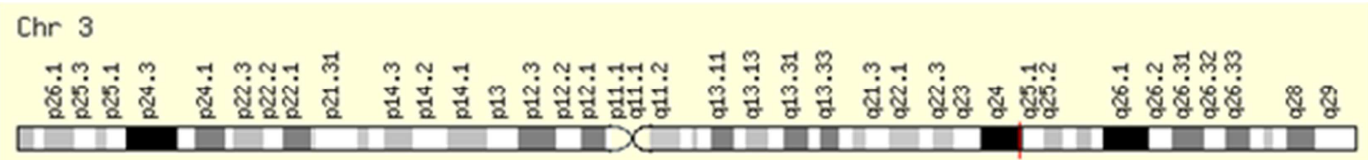

Figure 7. localization of the AT2R1 gene on chromosome 3.

The expression products of genes $A C E, A T 2 R 1$ interact synergistically in the maintenance of vascular and cellular homeostasis, the functional state of the endothelium, and blood circulation process as a whole. Thus, the studies of the genes encoding the Phase II detoxification enzymes synthesis (glutathione-S-transferases superfamily, acetyltransferases), as well as genes involved in the regulation of vascular tone, is relevant for patients with asthma, as it will help to predict personal disease course and response to therapy.

The purpose of the study was to determine the effect of polymorphisms of the genes of the phase II detoxification system and genes of the cardiovascular tone GSTT1, GSTM1, GSTP1, ACE, eNOS, AT2R1, NAT2 on the severity of asthma in children. 


\section{Materials and Methods}

This work was funded by the state budget of Ukraine. The study was coordinated with the local Medical Ethics Committee of the NIPhP NAMS. Inclusion criteria were men and women aged 5-18 years with bronchial asthma, ability of the child or his or her parents (guardian) to adequately cooperate in the research process, written consent of the parents (guardians) to participate in the study.

Exclusion criteria are the presence of other serious diseases that significantly affect the patient's condition and course of asthma, age up to 5 years, refusal of parents (guardians) or/and patients to participate in scientific clinical studies. The diagnosis of asthma as defined by GINA criteria.

Blood sampling was carried out with further determination of GSTT1, GSTM1, GSTP1, ACE, eNOS, AT2R1, NAT2 gene polymorphisms.

\section{Results and Discussion}

The study included 163 children aged 5-18 years: 38 children with severe asthma (group I), 69 children with moderate BA (group II) and 56 children with mild BA (group III). The groups were statistically comparable in gender and age composition: $2 / 3$ were boys and $1 / 3$ girls, mostly aged $7-$ 14 years $(p>0,05)$. The frequency distribution of the studied genotypes did not differ significantly in the age groups of the surveyed children, so a cumulative analysis of the data, regardless of the age characteristics was undertaken (Table 1).

Table 1. Genotype distribution of the studied genes among children with asthma, with different severity of the disease.

\begin{tabular}{|c|c|c|c|c|c|c|}
\hline \multirow{2}{*}{ Genotypes } & \multicolumn{2}{|c|}{ Group I, n=38 } & \multicolumn{2}{|c|}{ Group II, n=69 } & \multicolumn{2}{|c|}{ Group III, n=56 } \\
\hline & abs. & $\%$ & abs. & $\%$ & abs. & $\%$ \\
\hline \multicolumn{7}{|l|}{ GSTT1 } \\
\hline all & 31 & 81,58 & 50 & 72,46 & 40 & 71,43 \\
\hline del & 7 & 18,42 & 19 & 27,54 & 16 & 28,57 \\
\hline \multicolumn{7}{|l|}{ GSTM1 } \\
\hline all & 15 & 39,47 & 37 & 53,62 & 31 & 55,36 \\
\hline del & 23 & 60,53 & 32 & 46,38 & 25 & 44,64 \\
\hline \multicolumn{7}{|c|}{ GSTP1 A313G } \\
\hline $\mathrm{AA}$ & 18 & 47,37 & 35 & 50,72 & 23 & 41,07 \\
\hline $\mathrm{AG}$ & 17 & 44,74 & 28 & 40,58 & 28 & 50,00 \\
\hline GG & 3 & 7,89 & 6 & 8,70 & 5 & 8,93 \\
\hline \multicolumn{7}{|l|}{$\mathrm{ACE} \mathrm{I} / \mathrm{D}$} \\
\hline II & 6 & 15,79 & 17 & 24,64 & $21^{* \#}$ & 37,50 \\
\hline ID & 15 & 39,47 & 28 & 40,58 & 32 & 57,14 \\
\hline DD & 17 & 44,74 & 24 & 34,78 & $3^{* \#}$ & 5,36 \\
\hline \multicolumn{7}{|l|}{ AT2R1 } \\
\hline AA & 12 & 31,58 & 25 & 36,23 & $33^{* \#}$ & 58,93 \\
\hline $\mathrm{AC}$ & 15 & 39,47 & 38 & 55,07 & $20^{\#}$ & 35,71 \\
\hline $\mathrm{CC}$ & 11 & 28,95 & 6 & 8,70 & $3^{*}$ & 5,36 \\
\hline \multicolumn{7}{|c|}{ eNOS T-786C } \\
\hline TT & 11 & 28,95 & 27 & 39,13 & 25 & 44,64 \\
\hline $\mathrm{TC}$ & 19 & 50,00 & 36 & 52,17 & 21 & 37,50 \\
\hline $\mathrm{CC}$ & 8 & 21,05 & 6 & 8,70 & 10 & 17,86 \\
\hline \multicolumn{7}{|l|}{ eNOS $4 \mathrm{~b} / 4 \mathrm{a}$} \\
\hline $4 b / 4 b$ & 22 & 57,89 & 44 & 63,77 & 40 & 71,43 \\
\hline $4 b / 4 a$ & 15 & 39,47 & 24 & 34,78 & 15 & 26,79 \\
\hline $4 a / 4 a$ & 1 & 2,63 & 1 & 1,45 & 1 & 1,79 \\
\hline \multicolumn{7}{|l|}{ NAT2 C41T } \\
\hline $\mathrm{CC}$ & 15 & 39,47 & 24 & 34,78 & 16 & 28,57 \\
\hline
\end{tabular}

\begin{tabular}{|c|c|c|c|c|c|c|}
\hline \multirow{2}{*}{ Genotypes } & \multicolumn{2}{|c|}{ Group I, n=38 } & \multicolumn{2}{|c|}{ Group II, n=69 } & \multicolumn{2}{|c|}{ Group III, n=56 } \\
\hline & abs. & $\%$ & abs. & $\%$ & abs. & $\%$ \\
\hline CT & 19 & 50,00 & 37 & 53,62 & 33 & 58,93 \\
\hline TT & 4 & 10,53 & 8 & 11,59 & 7 & 12,50 \\
\hline \multicolumn{7}{|c|}{ NAT2 G857A } \\
\hline GG & 33 & 86,84 & 68 & 98,55 & 54 & 96,43 \\
\hline GA & 5 & 13,16 & $1^{*}$ & 1,45 & $2^{*}$ & 3,57 \\
\hline $\mathrm{AA}$ & - & - & - & - & - & - \\
\hline
\end{tabular}

As it can be seen from table 1, both telecine and allelic polymorphism of genes GSTT1 and GSTM1 were equally distributed between the groups, although there was a significant trend toward greater frequency of the GSTT1 gene deletion polymorphism among patients of the group II and the group III, and on the contrary, deletion polymorphism of the gene GSTM in group I, among the patients with more severe asthma. Frequency distribution of the polymorphic variant of the gene GSTP1 (A313G) did not differ.

Assessment of the influence of the genetic component on the severity of asthma in the groups of examined children found a significant contribution of the $A C E$ and $A T 2 R 1$ gene polymorphism.

With the presence of the $D D$ genotype in the $A C E$ gene $(\chi 2=18,67, \mathrm{p}=0,001, \mathrm{OR}=14,395 \% \mathrm{CI}(3,79-53,93)$ and $\mathrm{CC}$ in AT2R1 gene $(\chi 2=8,17, p=0,004, O R=7,295 \%$ CI $(1,85-$ $27,99)$ ) the risk of severe asthma increased 14,3 and 7,2 times in comparison with group III. For children with mild BA (group III) the protective effect of the $I I$ genotype in the $A C E$ gene was found $(\chi 2=4,21, \mathrm{p}=0,040, \mathrm{OR}=0,31$ and $95 \%$ CI (of 0,11 to 0,87$)$ ) and $A A$ in the $A T 2 R 1$ gene $(\chi 2=5,73$, $\mathrm{p}=0,017, \quad \mathrm{OR}=0,32 \quad 95 \% \quad \mathrm{CI} \quad(0,14-0,77)) \quad$ up to the development of the severe asthma.

In the group of children with moderate BA (group II) the $D D$ genotype in $A C E$ gene dominated $(\chi 2=14,12, \mathrm{p}=0,001$, $\mathrm{OR}=9,4295 \% \mathrm{CI}(2,66-33,36))$ and the $A C$ genotype in the gene $A T 2 R 1 \quad(\chi 2=3,91, \mathrm{p}=0,048 \quad \mathrm{OR}=2,21 \quad 95 \%$ CI $(1,07-$ $4,55)$ ) in comparison with the frequency distribution of these genotypes with children of the group III.

More severe bronchial asthma in children was also mediated by the polymorphic variants of the gene AT2R1: the prevalence of the $1166 S S$ genotype was higher in group I in contrast to group II $(\chi 2=7,52, p=0,011, \mathrm{OR}=4,2895 \% \mathrm{CI}$ $(1,44-12,75))$ and group III $(\chi 2=9,94, p=0,002, \mathrm{OR}=7,295 \%$ CI $(1,85-27,99))$. Frequency distribution of genotype $1166 A C$ prevailed in group II comparison with group III $(\chi 2=4,66, p=0,047, \mathrm{OR}=2,2195 \% \mathrm{CI}(1,07-4,55))$. Therefore, in the presence of genotype $1166 \mathrm{CC}$ for gene AT2R1 in children with moderate and easy BA can be considered as a disease deterioration risk group, and in the presence of genotype 1166AC for gene AT2R1 and mild BA is a group at risk of developing moderate severity asthma. That is, the heterozygous version of the gene AT2R1 with patients with bronchial asthma perjured moderate ASTHMA, and homozygote option 1166CC did the severe one.

There were no differences in the frequencies of 
distribution of polymorphic variants of the eNOS (T-786C, $4 b / 4 a)$ and NAT2 (C41T) genes in the comparison groups. The heterozygous variant of the NAT2(G857A) gene was not frequent in the examined groups but a significant increase was found in group I in comparison to group II $(\chi 2=6,35$, $\mathrm{p}=0,020, \mathrm{OR}=10,395 \% \mathrm{CI}(1,16-91,78))$, i.e. the $857 G A$ genotype is associated with a severe BA with more than 10 times increase in this risk, which, taking into consideration its low prevalence in the study groups, indicates that over $13,0 \%$ of children will have a severe BA mainly due to this genotype.
Having executed a preliminary analysis, the gene-gene interaction studies were performed in comparison groups depending on the severity of the disease in children. Additive interaction with $A C E$ and $A T 2 R 1$ genes was detected for GSTP1 gene. The $A C E$ and AT2R1 genes had an independent effect on the risk of moderate BA. An additive interaction was also determined for the NAT (C41T) and eNOS (4b/4a) genes.

Figure 8 presents the dendrogram characterizing the interaction of genes in the development of moderate BA compared to its mild form.

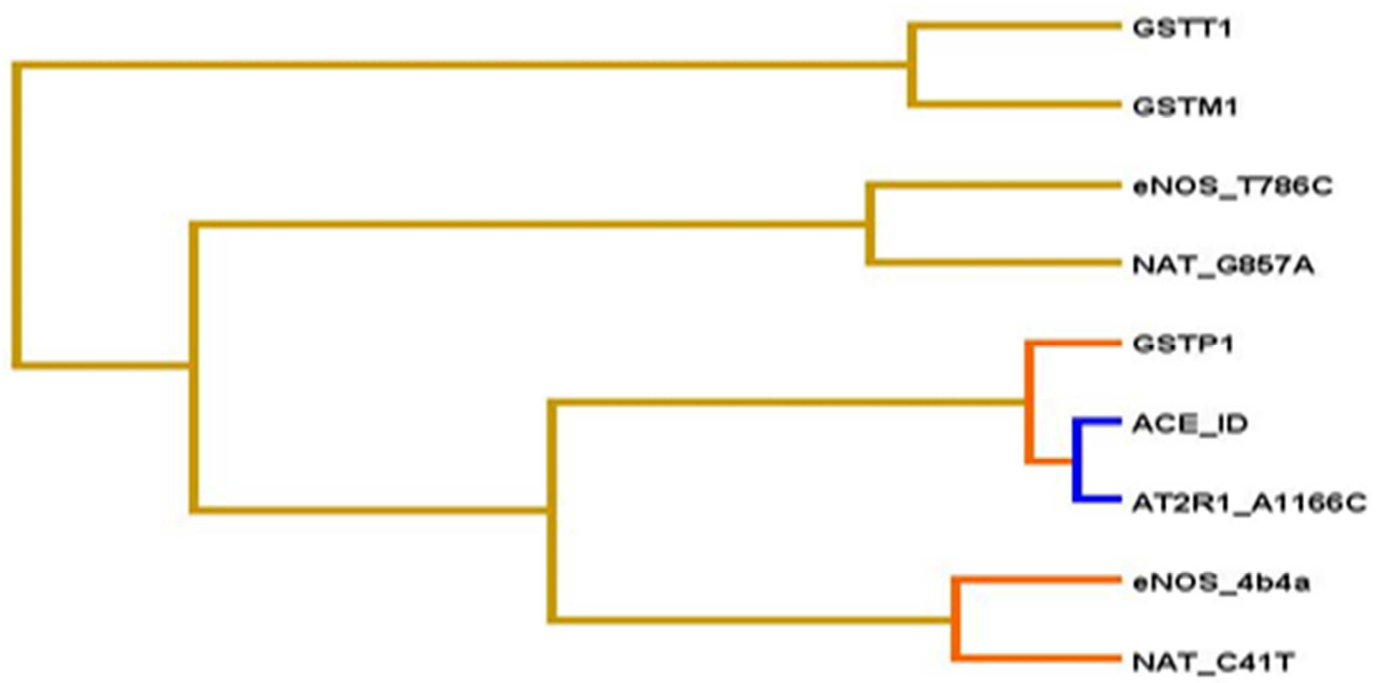

Figure 8. Dendrogram of gene-gene interaction in the development of moderate bronchial asthma versus mild one.

According to the results of the multifactor spatial reduction program, the best the entropy indicators appeared to be for the ACE and AT2R1 genes, with the $10.35 \%$ and $3.72 \%$, respectively. The entropy rate of the GSTP1 gene was quite low, but its interaction with the ACE gene increased the total entropy indicator by $4.19 \%$.

To assess the plausibility of possible statistical models in BA disease prognosis with the examined children, we conducted a permutation test, which was used to determine the statistical significance of all possible models of genegene interaction. A significant model in the prediction of the moderate BA type in children is the two-component one, which contained the GSTP1 and ACE genes. This model demonstrated high rates: $100 \%$ reproducibility and $72,67 \%$ prediction accuracy (Table 2).

Table 2. The analysis of gene-gene interaction in predicting the likelihood of moderate BA in children.

\begin{tabular}{|c|c|c|c|}
\hline $\begin{array}{l}\text { Number of genes in the } \\
\text { model }\end{array}$ & Gene combinations in the predictive model & $\begin{array}{l}\text { Model } \\
\text { reproducibility }\end{array}$ & $\begin{array}{l}\text { Model } \\
\text { accuracy }\end{array}$ \\
\hline 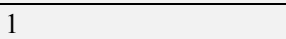 & $A C E$ & 0,6471 & $10 / 10$ \\
\hline $2 *$ & GSTP1_A313GACE & 0,7267 & $10 / 10$ \\
\hline 3 & GSTP1_A313GACEAT2R1_A1166C & 0,5862 & $5 / 10$ \\
\hline 4 & GSTP1_A313GACE eNOS_T786CNAT_C41T & 0,5611 & $4 / 10$ \\
\hline 5 & GSTP1_A313GACE eNOS_4b4aAT2R1_A1166CNAT_C41T & 0,6302 & $7 / 10$ \\
\hline 6 & GSTP1_A313GACE eNOS_T786CeNOS_4b4aAT2R1_A1166CNAT_C41T & 0,6401 & $10 / 10$ \\
\hline
\end{tabular}

Note. * - It appeared to be the best model among n-gene models $(\mathrm{p} \leq 0,05)$.

Having identified a statistically significant model, genotype combinations of GSTP1 and ACE genes involved in the program were analyzed (Table 3).

Table 3. The analysis of the distribution of genotype combinations by the studied genes in children with asthma in II (moderate asthma) and III (mild asthma) groups.

\begin{tabular}{|c|c|c|c|c|c|c|c|c|}
\hline \multirow{2}{*}{$\begin{array}{l}\text { Genotype } \\
\text { Combinations }\end{array}$} & \multicolumn{2}{|c|}{ Group II (n=69) } & \multicolumn{2}{|c|}{ Group III (n=56) } & \multicolumn{3}{|c|}{ Results of the statistical analysis } & \multirow[b]{2}{*}{$95 \%$ CI } \\
\hline & abs. & $\%$ & abs. & $\%$ & $\chi^{2}$ & $\mathbf{p}$ & OR & \\
\hline
\end{tabular}




\begin{tabular}{|c|c|c|c|c|c|c|c|c|}
\hline \multirow{2}{*}{$\begin{array}{l}\text { Genotype } \\
\text { Combinations }\end{array}$} & \multicolumn{2}{|c|}{ Group II $(n=69)$} & \multicolumn{2}{|c|}{ Group III $(n=56)$} & \multicolumn{3}{|c|}{ Results of the statistical analysis } & \multirow[b]{2}{*}{$95 \% \mathrm{CI}$} \\
\hline & abs. & $\%$ & abs. & $\%$ & $\chi 2$ & $\mathbf{p}$ & OR & \\
\hline $\mathrm{AA}+\mathrm{II}$ & 6 & $8,70^{*}$ & 15 & 26,8 & 6,00 & 0,014 & 0,26 & $0,09-0,73$ \\
\hline $\mathrm{AA}+\mathrm{ID}$ & 16 & 23,19 & 7 & 12,5 & 1,69 & 0,193 & 2,11 & $0,80-5,57$ \\
\hline $\mathrm{AA}+\mathrm{DD}$ & 13 & $18,84 *$ & 1 & 1,8 & 7,41 & 0,006 & 12,77 & $1,61-100,95$ \\
\hline $\mathrm{AG}+\mathrm{II}$ & 8 & 11,59 & 5 & 8,9 & 0,04 & 0,849 & 1,34 & $0,41-4,34$ \\
\hline $\mathrm{AG}+\mathrm{ID}$ & 10 & $14,49 *$ & 21 & 37,5 & 7,58 & 0,006 & 0,28 & $0,12-0,67$ \\
\hline $\mathrm{AG}+\mathrm{DD}$ & 10 & $14,49 *$ & 2 & 3,6 & 4,25 & 0,038 & 5,00 & $1,05-23,81$ \\
\hline $\mathrm{GG}+\mathrm{ID}$ & 2 & 2,90 & 4 & 7,1 & 0,44 & 0,506 & 0,39 & $0,07-2,24$ \\
\hline $\mathrm{GG}+\mathrm{DD}$ & 1 & 1,45 & 0 & 0,0 & 0,01 & 0,916 & & \\
\hline \multicolumn{9}{|l|}{$\mathrm{AT} 2 \mathrm{R} 1+\mathrm{ACE}$} \\
\hline $\mathrm{AA}+\mathrm{II}$ & 8 & 11,59 & 10 & 17,9 & 0,54 & 0,462 & 0,60 & $0,22-1,65$ \\
\hline $\mathrm{AA}+\mathrm{ID}$ & 14 & $20,29 *$ & 22 & 39,3 & 4,55 & 0,033 & 0,39 & $0,18-0,87$ \\
\hline $\mathrm{AA}+\mathrm{DD}$ & 3 & 4,35 & 1 & 1,8 & 0,12 & 0,732 & 2,62 & $0,6-25,91$ \\
\hline $\mathrm{AC}+\mathrm{II}$ & 8 & 11,59 & 10 & 17,9 & 0,54 & 0,462 & 0,60 & $0,22-1,65$ \\
\hline $\mathrm{AC}+\mathrm{DD}$ & 17 & $24,64 *$ & 1 & 1,8 & 11,31 & 0,001 & 17,98 & $2,31-140,0$ \\
\hline $\mathrm{CC}+\mathrm{II}$ & 1 & 1,45 & 1 & 1,8 & 0,32 & 0,570 & 0,81 & $0,05-13,23$ \\
\hline $\mathrm{CC}+\mathrm{ID}$ & 1 & 1,45 & 1 & 1,8 & 0,32 & 0,570 & 0,81 & $0,05-13,23$ \\
\hline $\mathrm{CC}+\mathrm{DD}$ & 4 & 5,80 & 1 & 1,8 & 0,46 & 0,497 & 3,38 & $0,37-31,18$ \\
\hline
\end{tabular}

Note. * - probably with group III $(\mathrm{p}<0.05)$.

Table 3 shows that in group III, compared to group II, there was an increase in the rate of GSTP1 $+A C E$ of the $A A$ $+I I$ genotypes combination spread, which was $26,8 \%$ and $8,7 \%$, respectively. Thus, a protective effect was established for this combination of genotypes, and a reduction in the risk of moderate-severity of BA disease was confirmed via calculating the odds ratio $(\chi 2=6,0, \mathrm{p}=0,001, \mathrm{OR}=0,2695 \%$ CI $(3,79-53,93))$. The frequency of GSTP1 1 ACE Combination spread of the $A G+D D$ genotypes in Group III was $3,6 \%$ and was significantly lower than in Group II, i.e., for this combination an association with 4-fold increase in the risk of moderate BA was found/established $(\chi 2=4,25$, $\mathrm{p}=0,037, \mathrm{OR}=5,2695 \% \mathrm{CI}(1,05-23,81))$ The combination of $G S T P 1+A C E$ of the $A G+I D$ genotypes, on the contrary, had a protective effect up to the aggravation of the disease.

The combination of polymorphic variants of the $A T 2 R 1$ and $A C E$ genes also had an important influence on the asthma course - in the presence of a combination of their $1166 A C+D D$ genotypes, the risk of moderate forms of asthma in children increased almost 18 times.

To determine the effect of gene-gene interaction on the development of severe forms of asthma in children, we compared the results of genetic testing of group III and group I patients.

In the development of the severe forms of BA, an additive gene-gene interaction between the GSTT1 and eNOS (4b/4a) genes was found. The NAT2 (C41T) gene interacted with a node formed by the leading factors in the development of more severe BA forms - the $A C E$ and $A T 2 R 1$ genes, which were characterized by independent (or isolated) influence, without intensifying interaction.

The dendrogram of gene-gene interaction in the development of the severe forms of BA compared to the mild form of the disease is shown in Figure 9.

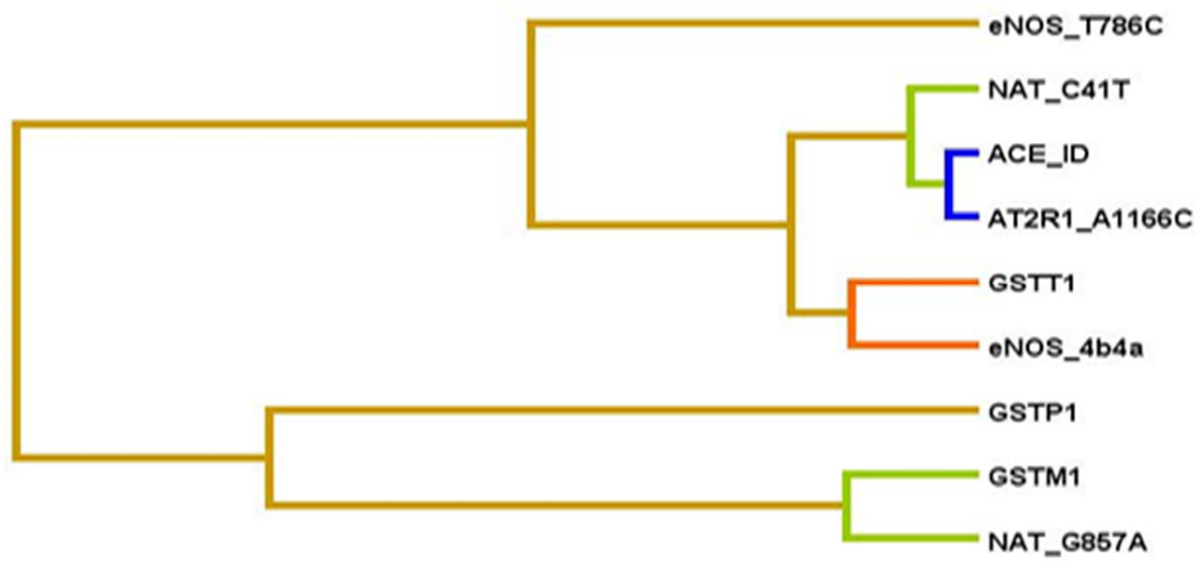

Figure 9. Dendrogram of gene-gene interaction in the development of severe forms of bronchial asthma compared with mild disease.

The entropy rates were the highest for the ACE genes - 17,82\% and $A T 2 R 1-10,22 \%$. The entropy rates for the genes with the detected interaction are low: GSTT1 gene $(0,99 \%), 4 b / 4 a$ polymorphism of eNOS gene $(1,41 \%)$, T786C polymorphism of eNOS gene (1,88\%), but they almost doubled under conditions of additive action of genes (Figure 10). 


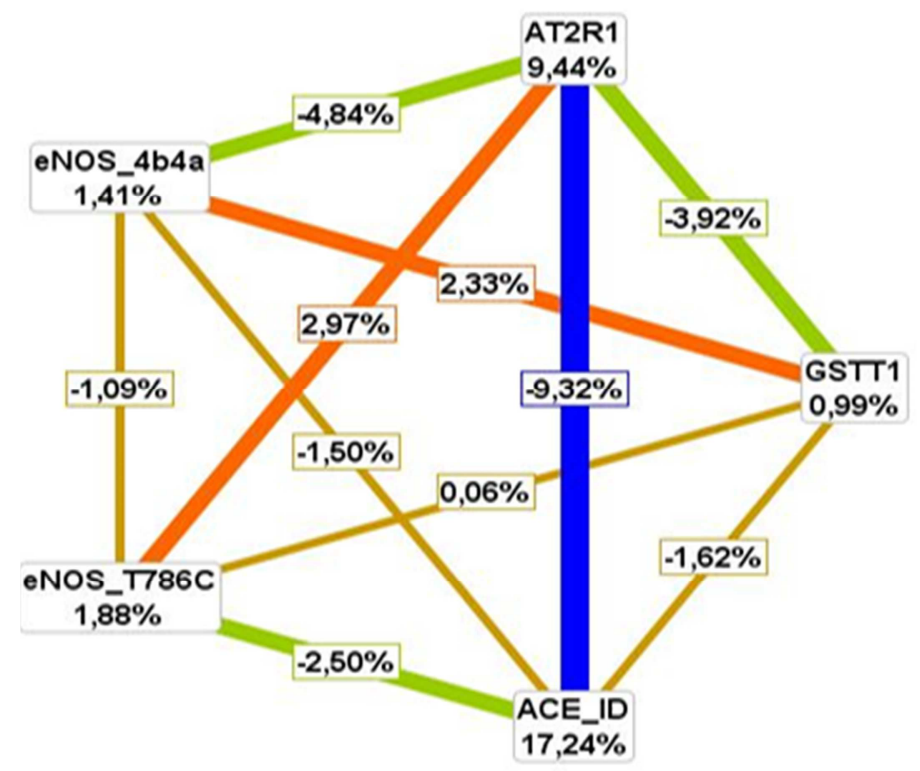

Figure 10. Specification of gene-gene interaction in the development of severe forms of bronchial asthma compared with the mild form of the disease.

The predictive value of possible mathematical models in predicting the risk of severe asthma was investigated using a permutation test (Table 4).

Table 4. Analysis of gene-gene interaction in the prediction of severe BA in children.

\begin{tabular}{llll}
\hline Number of genes in the model & Gene combinations in the predictive model & Model reproducibility & Model accuracy \\
\hline $1^{*}$ & $A C E_{-} I D$ & 0,6969 & $10 / 10$ \\
2 & $A C E_{-} I D$ eNOS_4b4a & 0,6476 & $6 / 10$ \\
3 & $A C E_{-} I D$ eNOS_T786CAT2RI & 0,5851 & $4 / 10$ \\
$4^{*}$ & $A C E_{-} I D$ eNOS_T786C eNOS_4b4a AT2RI & 0,6767 & $10 / 10$ \\
5 & $G S T T 1 A C E \_I D e N O S \_T 786 C$ CNOS_4b4aAT2RI & 0,5785 & $10 / 10$ \\
\hline
\end{tabular}

Note. * - the best model among $n$-gene models, $(\mathrm{p} \leq 0,05)$.

The reliable prognostic models in prediction of the risk of developing severe forms of BA in children were established to be one-line and four-locus models, which differed in the number of genes involved in the prediction. Both models had high accuracy $-100,0 \%$ and almost did not differ in their reproducibility $-69,69 \%$ and $67,67 \%$, respectively. In the study of genotype combinations for genes involved in prognostic models, the associations of patients with genotype combinations that reduced or increased the risk of developing severe BA in the examined children were identified (Table 5).

Table 5. Analysis of the distribution of genotype combinations by the studied genes among children with asthma in the I (severe asthma) and III (mild asthma) groups.

\begin{tabular}{|c|c|c|c|c|c|c|c|c|}
\hline \multirow[t]{2}{*}{ Genotype combinations } & \multicolumn{3}{|c|}{ Group I $(n=38)$} & \multicolumn{2}{|c|}{ Group III $(n=56)$} & \multicolumn{3}{|c|}{ Results of the statistical analysis } \\
\hline & abs. & $\%$ & abs. & $\%$ & $\chi^{2}$ & $\mathbf{p}$ & OR & $95 \% \mathrm{CI}$ \\
\hline \multicolumn{9}{|l|}{ AT2R1 A1166C + ACE I/D } \\
\hline $\mathrm{AA}+\mathrm{II}$ & 2 & 5,26 & 10 & 17,9 & 2,19 & 0,139 & 0,26 & $0,05-1,24$ \\
\hline $\mathrm{AA}+\mathrm{ID}$ & 8 & 21,05 & 22 & 39,3 & 2,68 & 0,102 & 0,41 & $0,16-1,06$ \\
\hline $\mathrm{AA}+\mathrm{DD}$ & 2 & 5,26 & 1 & 1,8 & 0,12 & 0,731 & 3,06 & $0,27-34,95$ \\
\hline $\mathrm{AC}+\mathrm{II}$ & 3 & 7,89 & 10 & 17,9 & 1,14 & 0,285 & 0,39 & $0,10-1,54$ \\
\hline $\mathrm{AC}+\mathrm{ID}$ & 5 & 13,16 & 9 & 16,1 & 0,01 & 0,925 & 0,79 & $0,24-2,58$ \\
\hline $\mathrm{AC}+\mathrm{DD}$ & 7 & $18,42 *$ & 1 & 1,8 & 6,05 & 0,014 & 12,42 & $1,46-105,67$ \\
\hline $\mathrm{CC}+\mathrm{II}$ & 1 & 2,63 & 1 & 1,8 & 0,20 & 0,653 & 1,49 & $0,09-24,52$ \\
\hline $\mathrm{CC}+\mathrm{ID}$ & 2 & 5,26 & 1 & 1,8 & 0,12 & 0,731 & 3,06 & $0,27-34,95$ \\
\hline $\mathrm{CC}+\mathrm{DD}$ & 8 & $21,05^{*}$ & 1 & 1,8 & 7,61 & 0,006 & 14,67 & $1,75-122,92$ \\
\hline \multicolumn{9}{|c|}{ AT2R1 A1166C + eNOS T786C } \\
\hline $\mathrm{AA}+\mathrm{TT}$ & 4 & 10,53 & 15 & 26,8 & 2,77 & 0,096 & 0,32 & $0,10-1,06$ \\
\hline $\mathrm{AA}+\mathrm{TC}$ & 4 & 10,53 & 14 & 25,0 & 2,20 & 0,138 & 0,35 & $0,11-1,17$ \\
\hline $\mathrm{AA}+\mathrm{CC}$ & 4 & 10,53 & 4 & 7,1 & 0,04 & 0,84 & 1,53 & $0,36-6,53$ \\
\hline $\mathrm{AC}+\mathrm{TT}$ & 2 & 5,26 & 10 & 17,9 & 2,19 & 0,139 & 0,26 & $0,05-1,24$ \\
\hline $\mathrm{AC}+\mathrm{TC}$ & 11 & 28,95 & 7 & 12,5 & 2,96 & 0,085 & 2,85 & $0,99-8,21$ \\
\hline $\mathrm{AC}+\mathrm{CC}$ & 2 & 5,26 & 3 & 5,4 & 0,20 & 0,654 & 0,98 & $0,16-6,17$ \\
\hline $\mathrm{CC}+\mathrm{TT}$ & 5 & $13,16^{*}$ & - & - & 5,28 & 0,022 & - & - \\
\hline
\end{tabular}




\begin{tabular}{|c|c|c|c|c|c|c|c|c|}
\hline \multirow[t]{2}{*}{ Genotype combinations } & \multicolumn{3}{|c|}{ Group I $(n=38)$} & \multicolumn{2}{|c|}{ Group III (n=56) } & \multicolumn{3}{|c|}{ Results of the statistical analysis } \\
\hline & abs. & $\%$ & abs. & $\%$ & $\chi^{2}$ & $\mathbf{p}$ & OR & $95 \% \mathrm{CI}$ \\
\hline $\mathrm{CC}+\mathrm{TC}$ & 4 & $10,53 *$ & - & - & 3,84 & 0,050 & - & - \\
\hline $\begin{array}{l}\mathrm{CC}+\mathrm{CC} \\
\text { eNOS } 4 \mathrm{~b} 4 \mathrm{a}+\mathrm{GSTT} 1\end{array}$ & 2 & 5,26 & 3 & 5,4 & 0,20 & 0,654 & 0,98 & $0,16-6,17$ \\
\hline $4 \mathrm{~b} 4 \mathrm{~b}+$ all & 20 & 52,63 & 27 & 48,2 & 0,04 & 0,834 & 1,19 & $0,52-2,72$ \\
\hline $4 b 4 b+$ del & 2 & $5,26^{*}$ & 13 & 23,2 & 4,18 & 0,041 & 0,18 & $0,04-0,87$ \\
\hline $4 b 4 a+$ all & 10 & 26,32 & 12 & 21,4 & 0,09 & 0,763 & 1,31 & $0,50-3,43$ \\
\hline $4 b 4 a+$ del & 5 & 13,16 & 3 & 5,4 & 0,91 & 0,340 & 2,68 & $0,60-11,95$ \\
\hline $4 a 4 a+$ all & 1 & 2,63 & 1 & 1,8 & 0,20 & 0,653 & 1,49 & $0,09-24,52$ \\
\hline $4 a 4 a+$ del & - & - & - & - & - & - & - & - \\
\hline
\end{tabular}

Note. ${ }^{*}$ - probably with group III $(\mathrm{p}<0,05)$.

In the analysis of gene-gene interactions in children of groups I and III differences related to the different distribution of combinations of genotypes of studied genes in children with different severity of BA were also identified (Figure 11).

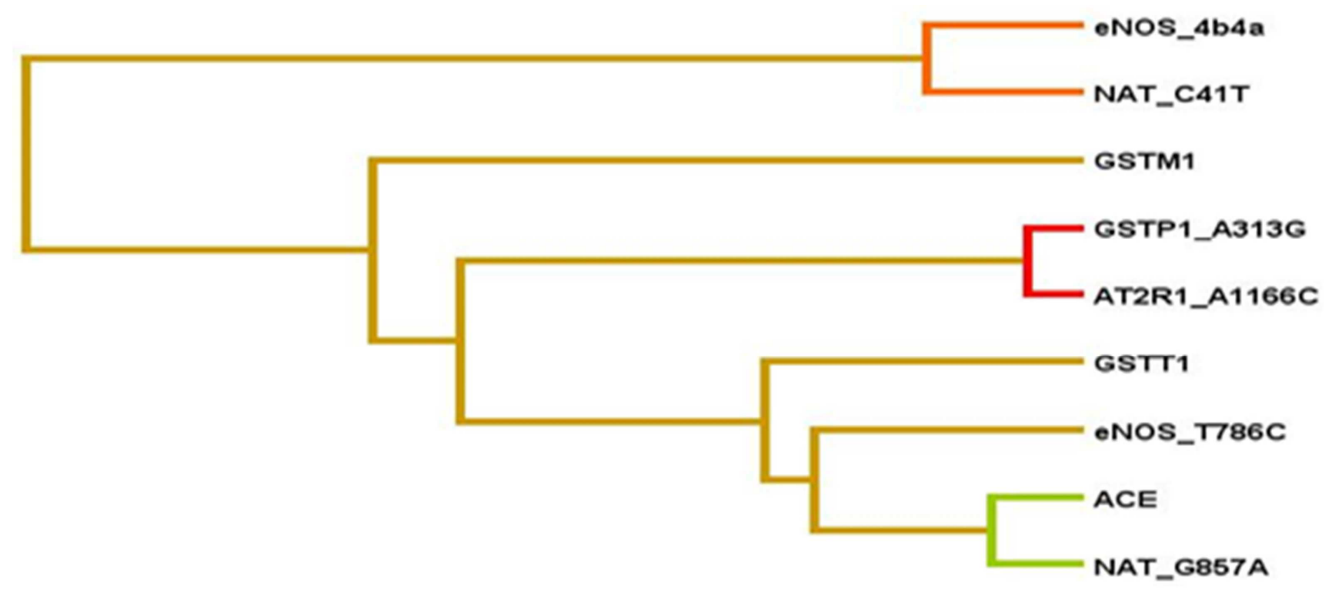

Figure 11. Dendrogram of gene-gene interaction in the development of severe forms of asthma compared with moderate forms of the disease.

The following figure 12 shows the genes with the highest entropy and additive interaction of genes in the increasing risk of severe forms.

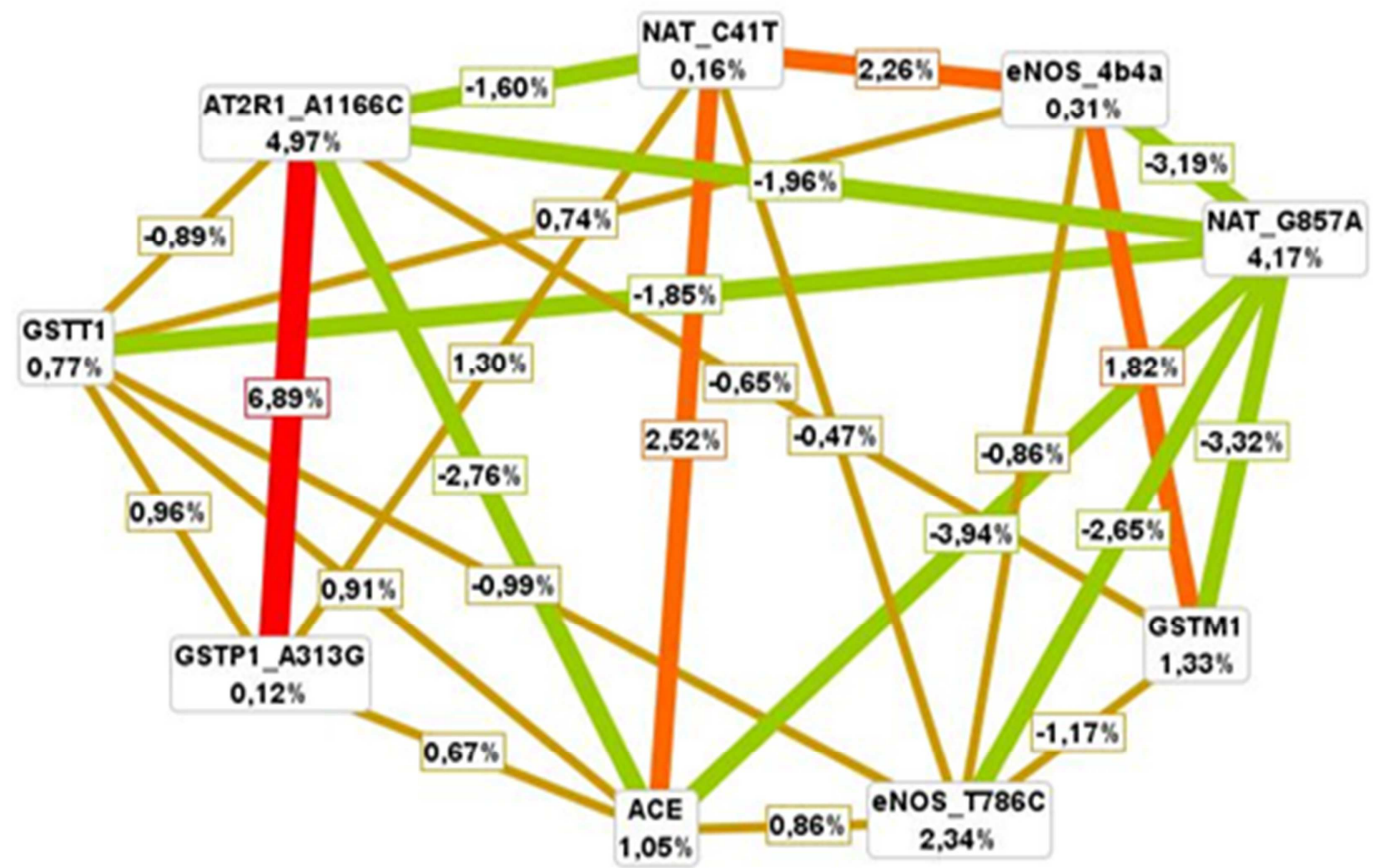

Figure 12. Specification of gene-gene interaction in the development of severe forms of bronchial asthma compared to moderate forms of the disease. 
It was proved that genotype combination $1166 A C+D D$ and $1166 C C+D D$ for the $A C E$ and $A T 2 R 1$ genes significantly affected the severity of the BA course and the development of severe forms of the disease in children, with the presence of which the risk increased from 12,5 to 14,5 times. It should be noted that the combination of genotypes $1166 C C+D D$ demonstrated a gradual increase in the comparison groups: $1,8 \%$ in group III, $5,8 \%$ in group II $21,05 \%$ in group I. These severity association markers are extremely important because among children with the most severe manifestations of the disease, they go up to almost $40,0 \%$, and in children with moderate severity manifestations of the disease, they go up to almost 30,0\%.

The Genes of vascular homeostasis strengthened unfavorable influence of polymorphic variants of genes of detoxification system, and the analysis of genotype combinations of these genes showed their differently directed participation in the severe course of the disease.

Reliable when calculating permutating test was a twocomponent model gene-gene interactions: GSTP1 (A313G), $A T 2 R 1$ (A1166C), the accuracy of which constituted $100,0 \%$, and repeatability of $68,94 \%$. Children in group I compared to group II, dominated by the prevalence of combination of genotypes $1166 C C+313 A A$ for AT2R1 genes and GSTP1 $(\chi 2=7,66, \mathrm{p}=0,023, \mathrm{OR}=7,5795 \% \mathrm{CI}$ $(1,49-38,54))$, and a combination $1166 C C+D D(\chi 2=5,73$, $\mathrm{p}=0,035, \mathrm{OR}=4,3395 \%$ CI $(1,21-15,52))$ (Table 6).

Table 6. Analysis of the prevalence of combinations of genotypes of studied genes among children, BA patients in I (severe asthma) and II (moderate asthma) groups.

\begin{tabular}{|c|c|c|c|c|c|c|c|c|}
\hline \multirow{2}{*}{$\begin{array}{l}\text { Genotype } \\
\text { Combinations }\end{array}$} & \multicolumn{2}{|c|}{ Group I, n=38 } & \multicolumn{2}{|c|}{ Group II, n=69 } & \multicolumn{3}{|c|}{ Results of the statistical analysis } & \multirow[b]{2}{*}{$95 \% \mathrm{CI}$} \\
\hline & abs. & $\%$ & abs. & $\%$ & $\chi^{2}$ & $\mathbf{p}$ & OR & \\
\hline \multicolumn{9}{|c|}{ AT2R1 A1166C+GSTP1 A313G } \\
\hline $\mathrm{CC}+\mathrm{AA}$ & 7 & $18,4^{*}$ & 2 & 2,90 & 7,66 & 0,023 & 7,57 & $1,49-38,54$ \\
\hline \multicolumn{9}{|c|}{ AT2R1 A1166C+ACE I/D } \\
\hline $\mathrm{CC}+\mathrm{DD}$ & 8 & $21,1 *$ & 4 & 5,80 & 5,73 & 0,035 & 4,33 & $1,21-15,52$ \\
\hline
\end{tabular}

Note. * - probably with group II, $(\mathrm{p}<0,05)$.

Thus, the results of molecular genetic studies identified genes that contribute to the development of severe BA in children. The functional allele of the GSTM1 gene (GSTM1 all) had a protective effect on the course of asthma because it was found almost twice as often among children with mild asthma. The deletion polymorphism of the GSTM1 gene is prevalent in individuals with severe BA.

The incidence of heterozygous GSTP1 gene polymorphism doubled already in moderate asthma and continued to increase during its severe course. Mutational polymorphism II in the monozygous state by the ACE gene and AA polymorphism by the AT II type 1 receptor gene (AT2R1 gene) was more frequently reported among children with mild BA than in its severe form $(\chi 2=7,77, \mathrm{p}=0,005, \mathrm{OR}=0,15$ $95 \%$ CI $(0,04-0,53))$. The AT2R1 gene $1166 C C$ genotype appeared among children with moderate BA and significantly increased in severe form, reaching $25,0 \%$, in the absence of such a mutation in mild BA. Polymorphism in the 1166 sequence of the receptor gene for angiotensin type II 1 alters the efficiency of the binding of second type angiotensin and, as a consequence, leads to increased vascular tone, endothelial dysfunction and, in our opinion, the smooth muscle tone of the bronchi, which leads to the formation of severity asthma in children.

\section{Conclusions}

In order to predict the course of bronchial asthma in children, it is advisable to perform genetic testing and to determine polymorphisms of genes of the enzymes of the phase II detoxification system (GSTT1, GSTM1, GSTP1, $N A T 2)$ and cardiovascular tone genes (AT2R1, ACE, eNOS).
The severity of bronchial asthma in children is depends on the $A C E(I / D)$ and $A T 2 R 1$ (A1166C) genes, and is also can be formed by the interaction of the eNOS, NAT2 (G857A), GSTT1 and GSTP1 genes.

The Severe at-risk bronchial asthma group of patients were those children with $A T 2 R 1$ (A1166C) CC, ACE (I/D) DD and $N A T$ (G857A) GA genotypes, and moderate-at-risk patients were the ones with $A T 2 R 1$ (A1166C) $A C$ and $A C E$ (I/D) DD genotypes.

To predict the course of moderate bronchial asthma in children, a two-component mathematical model of gene interaction with an accuracy of $100,0 \%$ was created, containing the GSTP1 (A313G) and AT2R1 (A1166C) genes. According to this model, the risk of developing severe asthma disease increased in case of the interaction for $C C$ with $A A$ genotypes of $A T 2 R 1$ and GSTP1genes, $C C$ with $D D$ genotypes of $A T 2 R 1$ and $A C E$ genes.

To predict the course of mild bronchial asthma in children, 3 mathematical models were created on the basis of statistically significant gene interaction. To determine the risk of the moderate disease, a two-component model with an accuracy of $72,7 \%$ was developed, which contains the GSTP1 and ACE genes. The following models have been developed to determine the risk of the severe disease: a single-stranded one within the $A C E$ gene and four-stranded with 100,0\% accuracy, containing $A C E$ (I/D), AT2R1 (A1166C), eNOS (T786C), eNOS (4b/4a) genes. In these models, the risk of developing moderate bronchial asthma increases in case of the interaction of $A A$ with $D D$ or $A G$ with $D D$ genotypes of GSTP1 and $A C E$ genes, $A C$ with $D D$ genotypes of $A T 2 R 1$ and $A C E$ genes, and the severe bronchial asthma increases in case of the interaction of $A C$ 
with $D D$ (12,5-fold) or $C C$ with $D D$ genotypes (14,5-fold) of $A T 2 R 1$ and $A C E$ genes, $C C$ with $T T$ or $C C$ with $T C$ genotypes of $A T 2 R 1$ and $e N O S$ (T786C) genes.

The $A A$ genotype of $A T 2 R 1$ (A1166C) gene, II genotype of $A C E$ (I/D) gene and the interaction of $4 b / 4 b$ with dell genotypes by eNOS $(4 b / 4 a)$ and GSTT1 genes were found to have a protective effect on the severity of bronchial asthma in children. Moderate asthma in children may be prevented by the interaction of $A A$ with $I I$ or $A G$ with $I D$ genotypes of GSTPI and $A C E$ gene, $A A$ with $I D$ genotype of $A T 2 R I$ and $A C E$ gene.

\section{References}

[1] Global Strategy for Asthma Management and Prevention (2019 update). URL: https://ginasthma.org/wpcontent/uploads/2019/06/GINA-2019-main-report-June-2019wms.pdf.

[2] Miriam F. Moffatt et al. (2010). A large-scale, consortiumbased genomewide association study of asthma. N Engl J Med. 363: 1211-21. doi: 10.1056/NEJMoa0906312.

[3] Bossé Y., Hudson T. J. (2007). Toward a comprehensive set of asthma susceptibility genes. Annu. Rev. Med. 58: 171-84. doi: 10.1146/annurev.med.58.071105.111738.

[4] Vercelli D. (2008). Discovering susceptibility genes for asthma and allergy. Nat. Rev. Immunol. 8 (3): 169-82. doi: $10.1038 /$ nri2257.

[5] Castro M. et. al. (2018). The role of GSTT1 and GSTM1 gene polymorphisms in bronchial asthma. European Respiratory Journal. 52: PA4223. doi: 10.1183/13993003.congress-2018. PA4223.

[6] Turner S. et. al. (2018). Variants in genes coding for glutathione S-transferases and asthma outcomes in children. Pharmacogenomics. 19 (8): 707-713. doi: 10.2217/pgs-20180027.

[7] Jesenak M., Zelieskova M., Babusikova E. (2017). Oxidative Stress and Bronchial Asthma in Children - Causes or Consequences? Front. Pediatr. 24; 5: 162. doi.org/10.3389/fped.2017.00162.
[8] Ober C. (2016). Asthma Genetics in the Post-GWAS Era. Ann. Am. Thorac. Soc. Vol 13.1: S85-90. doi: 10.1513/AnnalsATS.201507-459MG.

[9] Lytvynets L. Y. (2013). Oxidative stress and antioxidant defense in children with varying degrees of bronchial asthma control. Child's health. 8: 71-74.

[10] Lisitsa A. V. et al. (2010). The dynamics of oxidative stress indicators in patients suffering from exacerbation of bronchial asthma during inhalation therapy with liposomal drugs. Pulmonology. 1: 74-79.

[11] Wang I. J., Tsai C. H., Chen C. H. (2011). Glutathione Stransferase, incense burning and asthma in children. Eur. $\begin{array}{lllll}\text { Respir. J. Vol. 37(6): 1371-77. doi: } & \end{array}$ 10.1183/09031936.00137210.

[12] Piacentini S., Polimanti R., Moscatelli B. (2012). Lack of Association Between GSTM1, GSTP1, and GSTT1 Gene Polymorphisms and Asthma in Adult Patients From Rome, Central Italy // J. Investig. Allergol. Clin. Immunol. 22. 4: 252-256.

[13] C. Hanene C. et al. (2007). Association of GST genes polymorphisms with asthma in Tunisian children. Mediators Inflam. 37: 1150-57. doi: 10.1155/2007/19564.

[14] Mahmoud M. I., Kassem H. S., Nashwa H. (2011). The association between glutathione S-transferase P1 polymorphisms and asthma in Egyptians. Alexandria Journal of Medicine. 47: 105-115. doi: 10.1016/j.ajme.2011.06.008.

[15] Angeline T., Isabel W., Tsongalis J. (2010). Endothelial nitric oxide gene polymorphisms, nitric oxide production and coronary artery disease risk in a south Indian population. Exp. $\begin{array}{llll}\text { Mol. } & \text { Pathol. } 89 & \text { (3): 205-208. doi: }\end{array}$ 10.1016/j.yexmp.2010.08.009.

[16] Crisan D., Carr J. (2000). Angiotensin I-Converting Enzyme. Genotype and Disease Associations. J. Mol. Diagn. 2 (3): 105-115. doi: 10.1016/S1525-1578(10)60624-1.

[17] Eryuksel E., Ceyhan B. B., Rifat B. (2009). Angiotensin converting enzyme gene polymorphism in Turkish asthmatic patients. Journal of Asthma. 46; 4: 335-338. doi.org/10.1080/02770900802660972. 